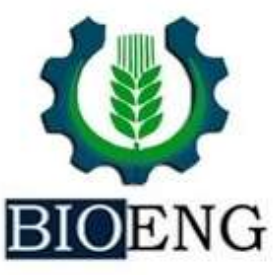

\title{
AMENIZAÇÃO DE ESTRESSE TÉRMICO VIA APLICAÇÃO DE BIOESTIMULANTE EM SEMENTES DE MELOEIRO CANTALOUPE
}

\author{
E. P. Vendruscolo*, A. P. B. Martins, L. F. C. Campos, A. Seleguini, \\ M. M. dos Santos
}

UFG - Univ Federal de Goiás, Escola de Agronomia, Goiânia, GO, Brasil

Article history: Received 10 June 2016; Received in revised form 30 July 2016; Accepted 02 August 2016; Available online 29 September 2016.

\section{RESUMO}

Objetivou-se obter informações a respeito da utilização de bioestimulante sobre a amenização do estresse térmico na fase de germinação e desenvolvimento inicial do meloeiro Cantaloupe. $\mathrm{O}$ estudo foi desenvolvido em esquema de blocos inteiramente casualizado, em esquema fatorial $4 \times 2$, composto pelas doses de bioestimulante $\left(0,4,8\right.$, e $\left.12 \mathrm{~mL} \mathrm{~L}^{-1}\right)$ e temperaturas $\left(25^{\circ} \mathrm{C}\right.$ e $\left.40^{\circ} \mathrm{C}\right)$. Foi avaliada a taxa de germinação, o tempo médio de germinação, o índice de velocidade de germinação, o crescimento inicial das plântulas e a massa seca de parte aérea e raiz de plântulas. Observou-se que a taxa de germinação foi favorecida pelo aumento das doses de bioestimulante em ambas as temperaturas. No entanto, a temperatura de $40^{\circ} \mathrm{C}$ interfere negativamente no tempo médio e no índice de velocidade de germinação. Houve efeito positivo para a aplicação de bioestimulante apenas para sementes submetidas à temperatura de $40^{\circ} \mathrm{C}$ sobre o tempo médio de germinação e o índice de velocidade de germinação, enquanto que na temperatura de $25^{\circ} \mathrm{C}$ o bioestimulante prejudicou o tempo médio de germinação. Portanto, o bioestimulante pode ser utilizado para melhorar o desenvolvimento inicial do meloeiro em regiões que apresentem altas temperaturas.

Palavras-chave: Cucumis melo L., reguladores vegetais, termoinibição

\section{THERMAL STRESS ALLEVIATION BY BIOSTIMULANT APPLICATION ON CANTALOUPE MELON SEEDS}

\begin{abstract}
It was aimed with this study obtain information on the use of biostimulant on the mitigation of heat stress in the germination phase and early development of muskmelon. The study was conducted in a randomized block design in a $4 \times 2$ factorial scheme composed by doses of biostimulant $\left(0,4,8\right.$, and $\left.12 \mathrm{~mL} \mathrm{~L}^{-1}\right)$ and temperatures $\left(25^{\circ} \mathrm{C}\right.$ and $\left.40^{\circ} \mathrm{C}\right)$. Were evaluated the germination rate, the average time of germination, germination speed index, the initial seedling growth and dry mass of shoot and root seedlings. It was observed that the germination rate was enhanced by increasing doses biostimulant at both temperatures. However, the temperature of $40^{\circ} \mathrm{C}$ impairs the average time and germination rate index. There was a positive effect for the biostimulant only for seeds subjected to $40^{\circ} \mathrm{C}$ on the average time of germination and germination speed index, while at $25^{\circ} \mathrm{C}$ the biostimulant hurt the average germination time. Therefore, the biostimulant can be used to improve the initial development of melons in regions with high temperatures.
\end{abstract}

Keywords: Cucumis melo L., plant growth regulators, thermoinhibition

*agrovendruscolo@gmail.com 


\section{INTRODUÇÃO}

O meloeiro (Cucumis melo L.) é uma cucurbitácea com expressão no mercado interno e importante produto de exportação. Segundo dados do Instituto Brasileiro Geografia e Estatística (IBGE, 2014), apenas no ano de 2014 o Brasil produziu aproximadamente $590 \mathrm{mil}$ toneladas em uma área de 22 mil hectares.

A região Nordeste é destaque na produção de melões, responsável por mais de $94 \%$ da produção nacional (IBGE, 2014). A região é caracterizada pelas elevadas taxas de radiação solar e altas temperaturas em grande parte do ano. Portanto, tendo em vista a realização de semeadura diretamente a campo, atividade comumente realizada em cultivos comerciais, a ocorrência de altas temperaturas nos locais de produção do meloeiro ultrapassam aquelas tidas como ideais para desenvolvimento da espécie segundo as Regras para Análise de Sementes (BRASIL, 2009), que estão no intervalo de 20 a $30^{\circ} \mathrm{C}$.

Apesar do clima seco, alta luminosidade e temperatura elevada que favorecem a produção de melões (FILGUEIRA, 2008), o fator temperatura pode ser um entrave relevante para a germinação e desenvolvimento inicial de muitas espécies hortícolas. Estudos demonstram que para as culturas de cenoura e alface foram observados efeitos deletérios na germinação quando as sementes foram expostas a temperatura de $35^{\circ} \mathrm{C}$ (NASCIMENTO \& PEREIRA, 2007; PEREIRA et al., 2007). Efeito denominado de termoinibição (NASCIMENTO, 2003).

A superação de estresses causados por fatores ambientais e antrópicos

\section{MATERIAL E MÉTODOS}

$\mathrm{O}$ estudo foi conduzido no laboratório de sementes da Escola de Agronomia da Universidade Federal de Goiás, situado na cidade de Goiânia, Estado de Goiás. O delineamento utilizado foi o de blocos inteiramente casualizados constitui um importante foco de pesquisa, tendo em vista a expansão das áreas cultivadas com espécies diversas, uso incorreto do solo e de insumos agrícolas e o comprometimento da produção de alimentos frente às alterações causadas pelo aquecimento global (MARENGO, 2014). Para tanto, produtos comerciais vêm sendo desenvolvidos a fim de possibilitar o melhor desenvolvimento de culturas em condições adversas. Os bioestimulantes constam como opções a serem relevadas.

A amenização de efeitos deletérios ligada a utilização de bioestimulante foi observada para a cultura do milho pipoca cultivado sob salinidade (OLIVEIRA et al., 2016) e para a cultura do girassol cultivado sob estresse por alumínio tóxico (COUTO et al., 2012). Também verificou-se melhora no vigor de sementes de soja (MORTELE et al., 2011), faveiro (CANESIN et al., 2012) quando tratadas previamente com o mesmo bioestimulante.

Esses resultados estão ligados às propriedades dos fitormônios que compõem o bioestimulante. Esses elementos atuam distintamente em diferentes tecidos, propiciando o incremento da expansão e da divisão celular, melhora da permeabilidade dos tecidos e no funcionamento das células vegetais (LARCHER \& PRADO, 2000; MORAIS et al., 2002; ÁVILA et al., 2008; TAIZ \& ZEIGER, 2013).

Frente ao exposto, o objetivo do trabalho foi avaliar doses crescentes de bioestimulante como amenizador do estresse térmico através da observação da germinação e do crescimento inicial de meloeiro nobre.

em esquema fatorial duplo $2 \times 4$. Os fatores de variação consistiram da utilização de duas temperaturas $\left(25^{\circ} \mathrm{C}\right.$ e $\left.40^{\circ} \mathrm{C}\right)$ e quatro doses de bioestimulante $(0 ; 4 ; 8$ e 12 $\left.\mathrm{mL} \quad \mathrm{L}^{-1}\right)$, totalizando 32 unidades experimentais. 
Sementes de meloeiro Cantaloupe, cultivar Trinity, foram obtidas de frutos colhidos na área experimental da Universidade, e armazenadas em ambiente seco e protegido da luz durante quatro meses. Verificou-se por meio de teste de germinação, segundo metodologia descrita nas Regras para Análise de Sementes (BRASIL, 2009), que o lote apresentou $94 \%$ de germinação.

$\mathrm{Na}$ ocasião da montagem do experimento, duzentas sementes foram transferidas para recipientes de vidro e submersas em soluções contendo bioestimulante nas respectivas doses dos tratamentos, por vinte minutos, enquanto que, para os tratamentos controle (dose 0 $\mathrm{mL} \mathrm{L}^{-1}$ de bioestimulante) as sementes foram mantidas apenas em água. Imediatamente após a imersão das sementes, estas foram retiradas da solução e deixadas por cinco minutos sobre peneira para eliminar o excesso de solução.

$\mathrm{O}$ bioestimulante utilizado foi $\mathrm{o}$ Stimulate ${ }^{\circledR}$, que contém em sua formulação $0,009 \%$ de cinetina (citocinina), $0,005 \%$ de ácido giberélico (giberelina), $0,005 \%$ de ácido indolbutiríco (auxina) e 99,981\% de ingredientes inertes (STOLLER DO BRASIL, 1998).

O teste de germinação foi realizado em quatro repetições de cinquenta sementes por tratamento. Foram utilizados rolos de papel germitest umedecidos com 2,5 vezes sua massa em água. Os conjuntos foram acondicionados em duas câmaras do tipo B.O.D com temperatura controlada a $25 \pm 0,2^{\circ} \mathrm{C}$ ou $40 \pm 0,2^{\circ} \mathrm{C}$. A germinação

\section{RESULTADOS E DISCUSSÃO}

Por meio da análise de variância foi observada resposta significativa da taxa de germinação às doses de bioestimulante e à interação entre os fatores estabelecidos para as variáveis tempo médio de germinação e índice de velocidade de germinação. Por outro lado, não se verificou diferenças no desenvolvimento inicial das plântulas provenientes de sementes expostas às diferentes doses de foi acompanhada diariamente, a partir do primeiro dia após a instalação do experimento, quanto foi obtida a primeira contagem, representada pela porcentagem de sementes germinadas. As contagens seguiram até $o$ oitavo dia para $o$ estabelecimento da taxa de germinação, tempo médio de germinação (LABOURIAU, 1983) e índice de velocidade de germinação (MAGUIRE, 1962).

Para a determinação do crescimento de plântulas foram utilizadas quatro repetições de 20 sementes por tratamento, dispostas em linha sobre duas folhas de papel germitest e recobertas com a adição de mais uma folha do papel. Em seguida, foram acondicionadas, na forma de rolos, nas mesmas condições àquelas do teste de germinação. Após oito dias foi mensurado o comprimento da parte aérea e raiz das plântulas, que ao final foram colocadas em sacos de papel separadamente para secagem em estufa com circulação de ar à temperatura de $80^{\circ} \mathrm{C}$, por um período de 24 horas. Após o período de secagem, ambas as partes das plântulas foram pesadas para a determinação da massa da matéria seca das mesmas.

Os dados foram submetidos à análise de variância e ao teste de Tukey a 5\% de probabilidade, quando relacionadas a fatores qualitativos (temperaturas). Enquanto que, para os fatores quantitativos (concentrações de bioestimulante), foram escolhidos modelos com base na significância dos coeficientes de regressão e no fenômeno biológico.

bioestimulante e acondicionadas a temperatura de $25^{\circ} \mathrm{C}$.

Observou-se que a taxa de germinação não foi afetado pelas temperaturas. No entanto, doses crescentes de bioestimulante, até $12,0 \mathrm{~mL} \mathrm{~L} \mathrm{~L}^{-1}$, proporcionaram aumento significativo na taxa de germinação de sementes de meloeiro (Figura 1). 


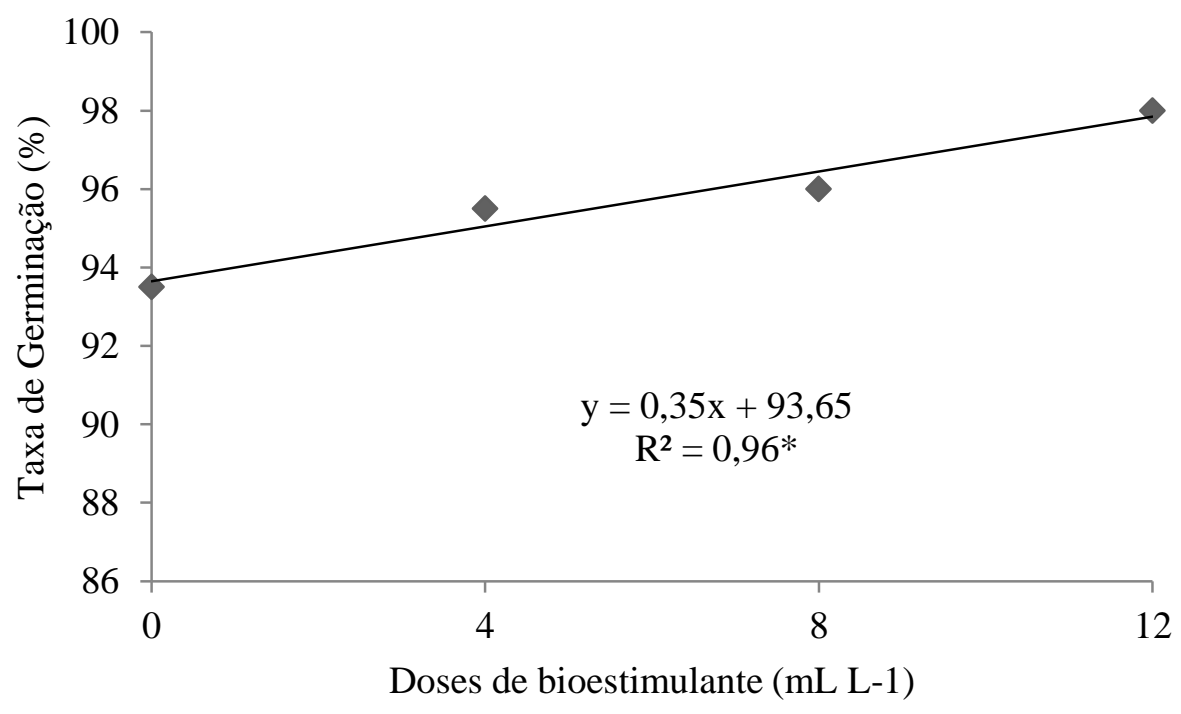

Figura 1. Taxa de germinação de sementes de meloeiro acondicionadas em duas temperaturas, em função de doses de bioestimulante. $\left(^{*}=\right.$ significativo a $5 \%$ de probabilidade).

O aumento da germinação pode ser resultado da ação dos fitormônios exógenos. Citocininas e giberelinas presentes no bioestimulante podem atuar diretamente sobre o alongamento e divisão celular (TAIZ \& ZEIGER, 2013). Giberelinas também são responsáveis pela indução da síntese do mRNA, que por sua vez é responsável pela síntese de nuclease, protease, $\alpha$-amilase, entre outras (MORAIS et al., 2002; ÁVILA et al., 2008). O bioestimulante pode ainda aumentar a permeabilidade do tegumento através da ação da auxina (LARCHER \& PRADO, 2000), permitindo maior hidratação e diminuindo a resistência do tegumento.

Verificaram-se interações entre os fatores de variação, doses de bioestimulante e temperatura, para as variáveis de tempo médio de germinação (TMG), índice de velocidade de germinação (IVG) e primeira contagem de sementes germinadas (PC). Em que, para a temperatura de $25^{\circ} \mathrm{C}$ observaram-se os melhores resultados, para todas as doses de bioestimulante utilizadas (Tabela 1).

A menor velocidade de germinação e menor número de sementes germinadas na primeira contagem foram observados na temperatura de $40^{\circ} \mathrm{C}$, muito provavelmente, está ligada a deterioração das sementes. Observou-se que as sementes, mantidas nessa temperatura, liberaram exsudados para o meio germinativo, propiciando a ocorrência de fungos. Esse resultado corrobora com as observações de STEINER et al. (2009) ao estudarem o efeito da temperatura sobre a germinação de rabanete. Esses autores verificaram que altas temperaturas $\left(35^{\circ} \mathrm{C}\right)$ tiveram efeito deletério sobre as sementes de rabanete, o que afetou, consequentemente, o crescimento inicial das plântulas.

O efeito deletério na velocidade da germinação em altas temperaturas também foi observado por LIMA et al. (2011) ao estudarem a combinação de temperaturas e substratos para germinação de Caesalpinia pyramidalis TUL. Os autores verificaram que, sementes mantidas em temperatura constante de $35^{\circ} \mathrm{C}$ apresentaram menores índices de velocidade de emergência.

Para o aumento das doses de bioestimulante verificou-se efeitos opostos, de acordo com a temperatura (Tabela 1). Para sementes tratadas com doses crescentes de bioestimulante e expostas à temperatura de $25^{\circ} \mathrm{C}$, houve efeito deletério, em que a maior dose de bioestimulante coincidiu com a ocorrência do maior tempo médio de germinação. Este resultado confirma que, em condições adequadas, a aplicação de fitormônios de 
forma exógena pode ser prejudicial ao desenvolvimento inicial do vegetal devido a um desbalanceamento hormonal, podendo levar a inibição do desenvolvimento celular (TAIZ \& ZEIGER, 2013).

Para sementes postas para germinar a temperatura de $40^{\circ} \mathrm{C}$, o aumento na concentração de bioestimulante foi benéfico, diminuindo o tempo médio para a germinação. Todavia, apesar da diminuição do tempo médio de germinação, mesmo na dose máxima utilizada, o bioestimulante não foi suficiente para a superação do estresse causado pela temperatura. $\mathrm{O}$ aumento da velocidade de germinação é benéfico, ao passo que sementes de germinação mais lenta são mais propícias aos danos causados por insetos, doenças ou condições do solo.

Para o índice de velocidade de crescimento, observou-se que apenas sementes acondicionadas a $40^{\circ} \mathrm{C}$ houve interferência das doses de bioestimulante (Tabela 1). Neste caso, assim como para a variável de tempo médio de germinação, maiores doses de bioestimulante, até a dose de $12,0 \mathrm{~mL} \mathrm{~L}^{-1}$, incrementaram a variável estudada.

Os resultados podem estar ligados a uma possível supressão dos estresses causados pela temperatura elevada. $\mathrm{O}$ aumento na velocidade de divisão e alongamento das células e o aumento da permeabilidade do tegumento das sementes, influenciadas pela atuação dos fitormônios (TAIZ \& ZEIGER, 2013), pode ter favorecido uma rápida emissão da radícula.

A análise dos dados da primeira contagem de sementes germinadas evidenciou acentuadamente o efeito amenizador do estresse térmico (Tabela 1). Apesar da resposta linear negativa das doses crescentes de bioestimulante sobre sementes acondicionadas em temperatura de $25^{\circ} \mathrm{C}$, para sementes mantidas a temperatura de $40^{\circ} \mathrm{C}$ a maior dose estudada incrementou em $18,5 \%$ a germinação de sementes, quando comparada ao tratamento sem a aplicação do bioestimulante.

Tabela 1. Valores médios de tempo médio de germinação (TMG), índice de velocidade de germinação (IVG) e primeira contagem de sementes germinadas (PC) de meloeiro nobre submetidas às temperaturas de $25^{\circ} \mathrm{C}$ e $40^{\circ} \mathrm{C}$ e doses de bioestimulante. Goiânia - GO, 2016.

\begin{tabular}{|c|c|c|c|c|c|c|}
\hline \multirow{2}{*}{$\begin{array}{c}\text { Doses } \\
\left(\mathrm{mL} \mathrm{L}^{-1}\right)\end{array}$} & \multicolumn{2}{|c|}{ TMG (dias) } & \multicolumn{2}{|c|}{ IVG } & \multicolumn{2}{|c|}{$\mathrm{PC}(\%)$} \\
\hline & $25^{\circ} \mathrm{C}$ & $40^{\circ} \mathrm{C}$ & $25^{\circ} \mathrm{C}$ & $40^{\circ} \mathrm{C}$ & $25^{\circ} \mathrm{C}$ & $40^{\circ} \mathrm{C}$ \\
\hline 0 & $1,26 a$ & $2,11 b$ & $41,50 \mathrm{a}$ & $23,42 b$ & $71,00 \mathrm{a}$ & $7,50 \mathrm{~b}$ \\
\hline 4 & $1,31 \mathrm{a}$ & $2,03 b$ & $40,17 \mathrm{a}$ & $25,21 \mathrm{~b}$ & $67,50 \mathrm{a}$ & $7,50 \mathrm{~b}$ \\
\hline 8 & $1,37 \mathrm{a}$ & $1,84 b$ & $40,79 a$ & $27,83 \mathrm{~b}$ & $66,50 \mathrm{a}$ & $18,50 \mathrm{~b}$ \\
\hline 12 & $1,38 \mathrm{a}$ & $1,80 \mathrm{~b}$ & $40,50 \mathrm{a}$ & $30,46 \mathrm{~b}$ & $65,50 \mathrm{a}$ & $26,00 \mathrm{~b}$ \\
\hline R. Linear & $*^{(1)}$ & $*^{(2)}$ & NS & $*(3)$ & $*^{(4)}$ & $*^{(5)}$ \\
\hline R. Quadrática & NS & NS & NS & NS & NS & NS \\
\hline DMS & \multicolumn{2}{|c|}{0,13} & \multicolumn{2}{|c|}{0,87} & \multicolumn{2}{|c|}{7,87} \\
\hline $\mathrm{CV} \%$ & \multicolumn{2}{|c|}{5,48} & \multicolumn{2}{|c|}{5,16} & \multicolumn{2}{|c|}{12,97} \\
\hline
\end{tabular}

Médias seguidas de mesma letra, nas linhas, não diferem entre si pelo teste de Tukey a 5\% de probabilidade. NS; * = Não significativo e significativo a $5 \%$ de probabilidade.

(1) $\mathrm{Y}=0,0106 \mathrm{x}+1,2625 \mathrm{R}^{2}=0,95 ;{ }^{(2)} \mathrm{Y}=-0,0277 \mathrm{x}+2,1118 \mathrm{R}^{2}=0,94 ;{ }^{(3)} \mathrm{Y}=0,5938 \mathrm{x}+$ $23,167 \mathrm{R}^{2}=0,99 ;{ }^{(4)} \mathrm{Y}=-0,4688 \mathrm{x}+70,375 \mathrm{R}^{2}=0,92 ;{ }^{(5)} \mathrm{Y}=1,6625 \mathrm{x}+4,9 \mathrm{R}^{2}=0,90$.

Para o teste de crescimento, não houve ajuste linear ou quadrático para os valores de comprimento de parte aérea, comprimento de raiz, massa seca de parte aérea e de raiz de plântulas de meloeiro submetidas aos diferentes tratamentos com bioestimulante e acondicionadas a $25^{\circ} \mathrm{C}$. Também não foi possível a avaliação de crescimento de plântulas mantidas à temperatura de $40^{\circ} \mathrm{C}$, devido à alta 
mortalidade, aproximadamente $100 \%$. Indicando que esta temperatura, apesar de não impedir a germinação, inibe o desenvolvimento das plântulas.

Resultados semelhantes foram obtidos por BELLO et al. (2008) ao estudarem $\mathrm{o}$ fator temperatura sobre a germinação de cerejeira. Os autores verificaram que à temperatura de $40^{\circ} \mathrm{C}$ não houve formação de plântulas normais, devido ao alto grau de deterioração

\section{CONCLUSÃO}

O bioestimulante, em concentração de até $12,0 \mathrm{~mL} \mathrm{~L}^{-1}$, pode ser utilizado para melhorar a germinação do meloeiro em condições de altas temperaturas. apresentado pelas sementes expostas a esta condição.

A influência negativa de altas temperaturas é relatada em diversos trabalhos, com uma grande variedade de culturas. Observa-se que, não apenas espécies são afetadas diferentemente pelas temperaturas, mas também cultivares de uma mesma espécie podem apresentar comportamentos distintos.

Não se recomenda a utilização do bioestimulante quando há condições de temperatura apropriadas ao desenvolvimento do meloeiro.

\section{AGRADECIMENTOS}

A Capes pela concessão da bolsa de doutorado ao primeiro autor.

\section{REFERÊNCIAS BIBLIOGRÁFICAS}

ÁVILA, M. R.; SCAPIM, C. A., ALBRECHT, L. P., TONIN, T. A., STÜLP, M. Bioregulator application, agronomic efficiency, and quality of soybean seeds. Scientia Agricola, v. 65(6): 604-612, 2008.

\section{BELLO, E. P. B. C. S., ALBUQUERQUE,} M. C. F.; GUIMARÃES, S. C., MENDONÇA, E. A. F. Germinação de sementes de Amburana acreana (Ducke) A. C. Sm. submetidas a diferentes condições de temperatura e de estresse hídrico. Revista Brasileira de Sementes, v. 30(3), 16-24, 2008.

BRASIL. Ministério da Agricultura. Regras para análise de sementes. Brasília: Departamento Nacional de Produção Vegetal, 2009. 399p.

CANESIN, Â.; MARTINS, J. M. D. T.; SCALON, S. D. P. Q.; MASETTO, T. E. Bioestimulante no vigor de sementes e plântulas de faveiro (Dimorphandra mollis Benth.). Cerne, v. 18(2): 309-315, 2012.

COUTO, C. A.; PEIXOTO, C. P.; VIEIRA, E. L.; CARVALHO, E. V.;
PEIXOTO, V. A. B. Action of cinetina, butyric acid and gibberellic acid on the emergency of sunflower under aluminum stress. Comunicata Scientiae, v. 3(3): 206-210, 2012.

FILGUEIRA, F. A. R. Novo manual de olericultura. 3 ed. 2008. 421p.

IBGE. Produção agrícola municipal. 2014. Disponível em: http://www.sidra.ibge.gov.br. Acesso em: 03 de abril de 2016.

LABOURIAU, L. G. A germinação de sementes. Washington: Secretaria Geral da Organização dos Estados Americanos. 1983. 174p.

LARCHER, W.; PRADO, C. H. D. A. Ecofisiologia vegetal. 2000. p. 341-418.

LIMA, C. R., PACHECO, M. V., BRUNO, R. D. L. A., FERRARI, C. S., BRAGA JÚNIOR, J. M., BEZERRA, A. K. D. Temperaturas e substratos na germinação de sementes de Caesalpinia pyramidalis TUL. Journal of Seed Science, v. 33(2), 216-222, 2012. 
MAGUIRE, J. D. Speed of germinationaid in selection and evaluation for seedlings emergence and vigor. Crop Science, v. 2(1), 176-177, 1962.

MARENGO, J. A. O futuro clima do Brasil. Revista USP, n. 103, p. 25-32, 2014.

MORAIS, C.R.A., MODOLO, V.A., CASTRO, P.R.C. Fisiologia da germinação. Em: CASTRO, P.R.C., SENA, J.O.A., KLUGE, R.A (Ed.) Introdução à fisiologia do desenvolvimento vegetal. 2002. p. 159-178.

MOTERLE, L. M., SANTOS, R. F., SCAPIM, C. A., DE LUCCA, A., BONATO, C. M., CONRADO, T. Efeito de biorregulador na germinação e no vigor de sementes de soja. Ceres, v. 58(5), 651660, 2011.

NASCIMENTO, W. M. Preventing thermoinhibition in a thermosensitive lettuce genotype by seed imbibition at low temperature. Scientia Agricola. v. 60(3), 477-480, 2003.

NASCIMENTO, W. M., PEREIRA, R. S. Testes para avaliação do potencial fisiológico de sementes de alface e sua relação com a germinação sob temperaturas adversas. Revista Brasileira de Sementes, v. 29(3), 175-179, 2007.

OLIVEIRA, F.D.A., MEDEIROS, J.F., CUNHA, R.C., LIMA SOUZA, M.W., LIMA, L.A. Uso de bioestimulante como agente amenizador do estresse salino na cultura do milho pipoca. Revista Ciência Agronômica, v. 47(2), 307-315, 2016.

PEREIRA R. S., NASCIMENTO W. M., VIEIRA J. V. Germinação e vigor de sementes de cenoura sob condições de altas temperaturas. Horticultura Brasileira, v. 25(1), 215-219, 2007.

STEINER, F., PINTO JÚNIOR, A. S., ZOZ, T., GUIMARÃES, V. F., DRANSKI, J. A., RHEINHEIMER, A. R. Germinação de sementes de rabanete sob temperaturas adversas. Revista Brasileira de Ciências Agrárias, v. 4(4), 430-434, 2009.
STOLLER DO BRASIL. Stimulate Mo em hortaliças: informativo técnico. 1998. $1 \mathrm{p}$.

TAIZ L., ZEIGER E. Fisiologia vegetal. 5 ed. 2013. 954p. 